\title{
The Nun protein of bacteriophage HKO22 inhibits translocation of Escherichia coli RNA polymerase without abolishing its catalytic activities
}

\author{
Siu Chun Hung ${ }^{1,3}$ and Max E. Gottesman ${ }^{1,2,4}$ \\ ${ }^{1}$ Department of Biochemistry and Molecular Biophysics, ${ }^{2}$ Institute of Cancer Research, Columbia University College of \\ Physicians and Surgeons, N ew York, N ew York 10032 USA
}

\begin{abstract}
Bacteriophage HK022 Nun protein blocks transcription elongation by Escherichia coli RNA polymerase in vitro without dissociating the transcription complex. Nun is active on complexes located at any template site tested. Ultimately, only the 3'-OH terminal nucleotide of the nascent transcript in an arrested complex can tum over; it is removed by pyrophosphate and restored with NTPS. This suggests that Nun inhibits the translocation of RNA polymerase without abolishing its catalytic activities. Unlike spontaneously arrested complexes, Nun-arrested complexes cannot be reactivated by transcription factor $G$ reB. The various complexes show distinct pattems of nucleotide incorporation and pyrophosphorolysis before or after treatment with Nun, suggesting that the configuration of RNAP, transcript, and template DNA is different in each complex.
\end{abstract}

[Key Words: Phage HK022; N un protein; RNA polymerase; transcription arrest; translocation]

Received June 23, 1997; revised version accepted August 26, 1997.

The product of the nun gene of prophage HK022 inhibits superinfection by the related coliphage $\lambda$ (Robert et al . 1987). The 13-kD Nun protein, like the $\lambda N$ antitermination protein, binds to the cis-acting $\lambda$ nut RNA elements through an arginine-rich binding motif (Chattopadhyay et al. 1995). In contrast to $\lambda N$, which suppresses transcription termination promoter-distal to nut, $\mathrm{N}$ un provokes termination downstream of these ele ments in both the $\lambda p_{L}$ and $p_{R}$ operons (Robert et al. 1987; Robledo et al. 1990; Sloan and Weisberg 1993). N un-induced transcription termination is inhibited by mutations in nut or in the trans-acting Escherichia coli proteins N usA, N usB, N usE, and N usG (Robert et al. 1987; Robledo et al. 1990, 1991; Baron and Weisberg 1992; E. Burova, S.C. Hung, and M.E. Gottesman, unpubl.).

Transcription arrest by $\mathrm{N}$ un has been duplicated in a defined cell-free system. Purified Nun protein is effective, al though the reaction is strongly stimulated by the four N us proteins (Hung and Gottesman 1995). The binding of $\mathrm{N}$ un protein to the stem-loop boxB sequence of $\lambda$ nut RNA and the effects of boxB mutations and deletions on $\mathrm{N}$ un binding and transcription arrest have been demonstrated in vitro (Chattopadhyay et al. 1995; Hung and Gottesman 1995). A mutation in N usG that

\footnotetext{
${ }^{3}$ Present address: Brigham and Women's Hospital, Boston, Massachusetts 02115 USA.

${ }^{4}$ Corresponding author.

E-MAIL gottesma@cuccfaccc.columbia.edu; FAX (212) 305-1741.
}

inhibits $\mathrm{N}$ un action in vivo abolishes $\mathrm{N}$ us-mediated stimulation of N un action in vitro (E. Burova, S.C. Hung, and M.E. Gottesman, unpubl.). Thus, the bi ol ogical properties of $\mathrm{N}$ un have been reproduced in vitro, with the exception that the arrested complex does not dissociate from the template in our cell-free system.

In this paper we describe how N un induces transcription arrest at defined template sites in vitro. We demonstrate that paused or stalled RNA polymerase (RNAP) complexes respond to $\mathrm{N}$ un in distinct ways. These data suggest that $\mathrm{N}$ un blocks the translocation of RNAP at a defined point in the elongation process.

\section{Results}

Effects of Nun on RNA polymerization

$\mathrm{N}$ un arrests elongating RN AP at or near intrinsic pause sites (Hung and Gottesman 1995). This may indicate that $\mathrm{N}$ un recognizes specific structural features of RN AP paused at such sites. Alternatively, $\mathrm{N}$ un modification of elongating RNAP may be a slow process, so that $\mathrm{N}$ un only arrests transcription complexes that dwell for an extended period at any template site. We distinguished between these possibilities using an interrupted el ongation strategy. Transcription elongation on a $\lambda p_{L}$ operon template was permitted for a brief period and then interrupted by the removal of NTPs (see M aterial s and M ethods for details). Under these conditions, many of the 
complexes paused at the 119-nucleoti de site, that is, contained a 119-nucleotide nascent transcript (Fig. 1A, Iane 1). The paused RNAP was then "walked" by repeated addition and removal of the appropriate NTP subsets to generate complexes stalled at sel ected downstream sites (Fig. 1B-G, lanes 1; see $M$ aterials and Methods for details). The stalled complexes were elongation proficient, as addition of the complete set of NTPs generated principally the 161-nucleotide and 162-nucleotide runoff transcripts (Fig. 1A-G, lanes 2). In addition, a 151nucleotide transcript, present in a spontaneously arrested complex, formed in all transcription assays (Fig. 1A-G; see below).

To determine whether these stalled complexes were susceptible to arrest, they were first preincubated with $\mathrm{N}$ un for $5 \mathrm{~min}$ and then chased with four NTPS. N ote that preincubation with $\mathrm{N}$ un did not alter the size of the transcript over this time period (Fig. 1A-G, lanes 1,3). With the addition of the four NTPs, all of the N un-pretreated complexes arrested (Fig. 1A-G, Ianes 2,4). With the exception of the 122-nucleotide arrested complex, which derives from the paused complex 119, none of the arrested complexes had been observed in an "uninterrupted" elongation assay (data not shown). This result indicates that $\mathrm{N}$ un can act on stalled or paused complexes and rules out the notion that the latter represent a particular $\mathrm{N}$ un-sensitive class of RN APs. Most complexes arrested after the incorporation of one or a few nucleotides. Complexes 125 and 126, however, arrested without further transcript elongation. The concentrations of chase NTPs affected neither the efficiency of arrest nor the number of nucleotides incorporated by the $\mathrm{N}$ un-treated complex prior to arrest (data not shown).
We next determined the kinetics of $\mathrm{N}$ un interaction with RNAP. N un was preincubated with complexes 122 and 126 for different periods of time prior to the addition of NTPs (Fig. 2A,B). Little or no arrest could be detected when N un and NTPs were added simultaneously (lanes 3). The efficiency of arrest increased with the time of preincubation with $\mathrm{N}$ un and reached a plateau after $>1$ min of preincubation (lanes 4-7). These data confirm that $\mathrm{N}$ un can arrest el ongating RN AP at any site, but the dwell time of the transcription complex at that site must be sufficient to allow interaction with $\mathrm{N}$ un.

Nun-induced transcription arrest and GreB-stimulated transcript cleavage

Transcription complexes located at certain sites tend to arrest spontaneously (Arndt and Chamberlin 1990). Such complexes are particularly sensitive to endonucleolytic transcript cleavage stimulated by the E. coli GreB protein (Borukhov et al. 1993). Transcript cleavage reactivates spontaneously arrested complexes, allowing elongation to continue from the new 3 '-OH terminal nucleotide (Borukhov et al. 1993; N udler et al. 1994). We asked if complexes arrested by $\mathrm{N}$ un could al so be reactivated by GreB.

Elongation complexes were incubated with approximately equimolar concentrations of GreB for $5 \mathrm{~min}$ (Fig. 3). Under these conditions, only the 126 and 151 complexes were GreB-sensitive. The 126-nucleotide transcript was cleaved to 122 and 124 nucleotides (lane 12). Recall that complex 126 was arrested by $\mathrm{N}$ un without transcript elongation (Fig. 1F). All other GreB-sensitive

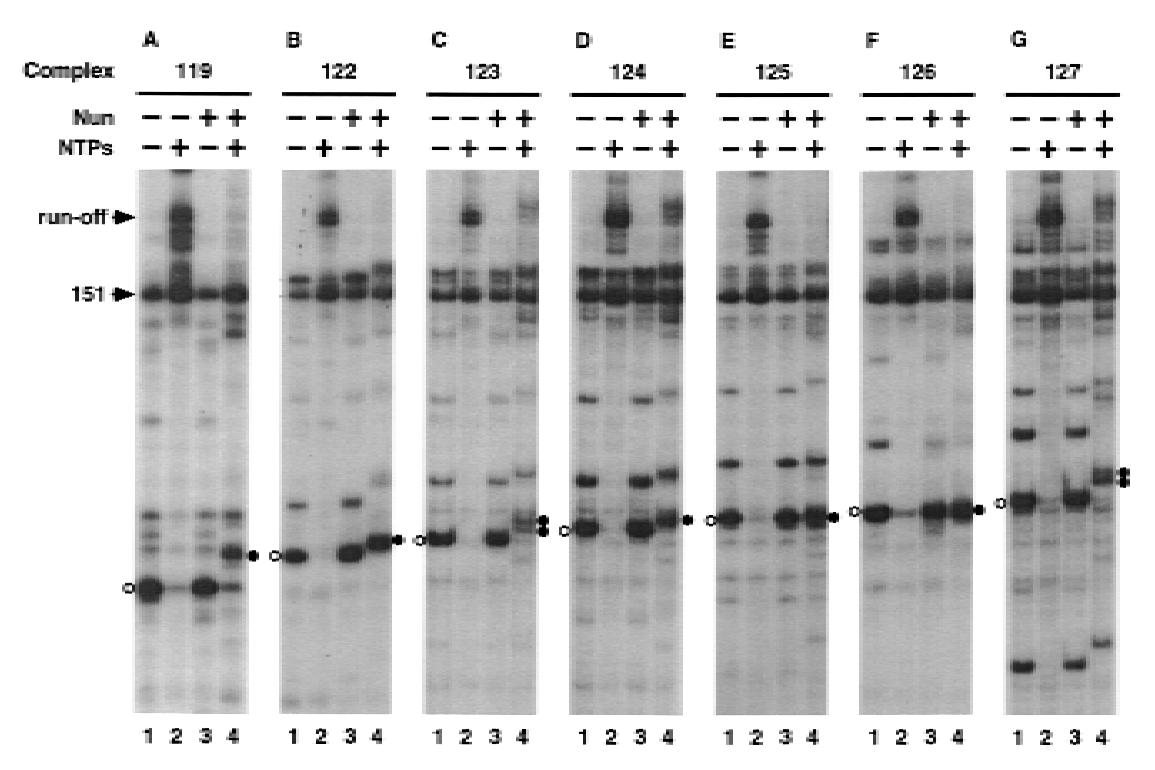

Figure 1. Nun-induced arrest of transcription elongation complexes. Transcription elongation complexes located at various positions on a $\lambda \mathrm{p}_{\mathrm{L}}$ operon template were prepared and designated as described in $\mathrm{Ma}$ terials and M ethods. Each panel shows the transcript of a complex located at a particuIar position (lanes 1) and the RNA product(s) after the complex was chased with NTPs (lanes 2), incubated with N un (lanes $3)$, and incubated with $\mathrm{Nun}$ and then chased with NTPs (lanes 4). In this and subsequent figures, the + or - sign in the lane description denotes the addition or omission, respectively, of the reagent shown to the far left of the sign. The descending order of lane descriptions corresponds to the order of treatments of the transcription complex. The pointers with run-off and 151 labels locate the runoff transcript and the 151-nucleotide transcript of the spontaneously arrested complex, respectively. In each panel, the transcript of the starting complex is located by $\bigcirc$ on the left, and the transcript(s) of the Nun-arrested complex(es) thus derived is located on the right. 


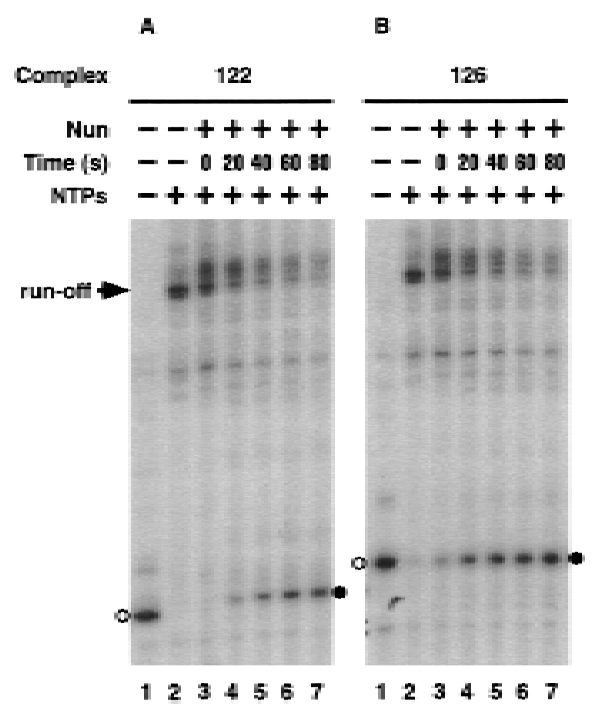

Figure 2. Time requirement of complex modification by $\mathrm{N}$ un transcription complexes 122 and 126 (lanes 1) were incubated with $\mathrm{N}$ un (lanes 3-7) for the indicated periods of time (Time) and were then chased with NTPs (Ianes 2-7).

complexes likewise arrested without nucleoti de addition (data not shown).

Transcription reactions performed with $\mathrm{N}$ un and $\mathrm{GreB}$ demonstrate that GreB does not block N un-mediated arrest and that the initial sensitivity or resistance of a transcript to GreB-induced cleavage is retained in the N unarrested complex. For example, the GreB-resistant complex 122 arrested after the incorporation of a single nucleotide in the presence or absence of GreB (Fig. 4A, lanes 1,4,8). The 123-nucleotide transcript was stable when the Nun-arrested complex was incubated with GreB (lane 10) and did not el ongate when the complex

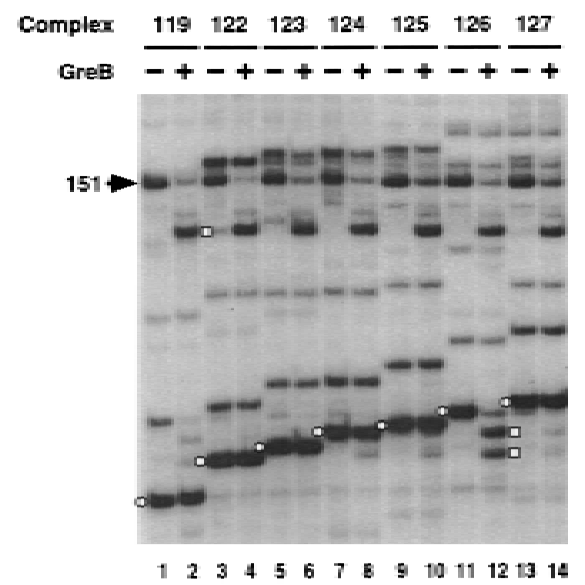

Figure 3. GreB-stimulated transcript cleavage of transcription complexes. Transcription complexes (odd-numbered lanes) were incubated with approximately equimolar (50 nM) of GreB (even-numbered lanes). The cleaved transcript is indicated $\square$ on the right.

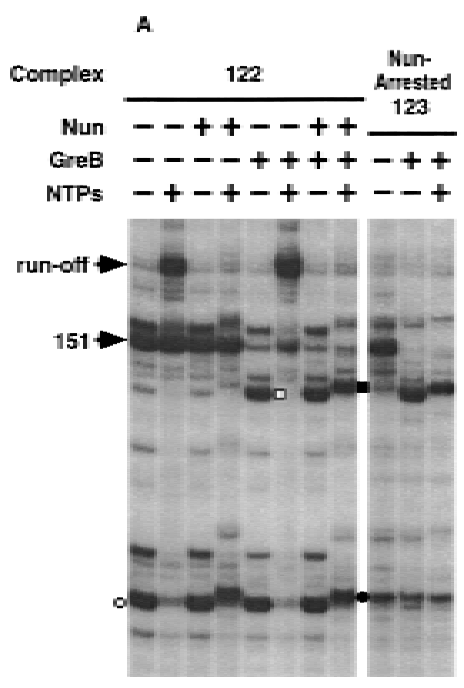

B

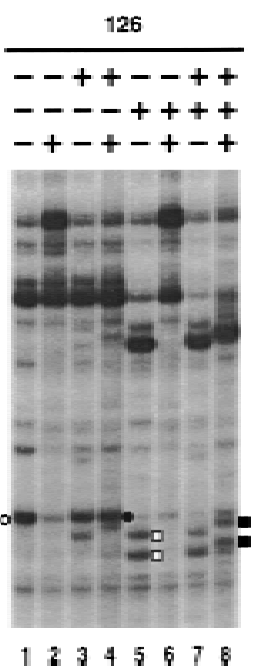

Figure 4. Effects of $\mathrm{GreB}$ on N un-induced transcription arrest. Transcription complexes 122 and 126 (lanes 1) were incubated with different combinations of Nun, GreB, and NTPs, as detailed in the lane descriptions (lanes 2-8). The N un-arrested complex with a 123-nucleotide transcript (N un-Arrested 123) used in the reactions shown in A (lanes 9-11), was prepared from the reaction shown in A (lane 4) after removal of unincorporated NTPs. The complex was incubated with GreB (lanes 10-11) and then chased with NTPs (Iane 11). (ם) The transcript of an arrested complex after treatment with $\mathrm{N}$ un and GreB.

was subsequently incubated with NTPs (lane 11). The GreB-sensitive 126 complex remained sensitive after exposure to Nun (Fig. 4B, lanes 1,5,7). However, the cleaved 122- and 124-nucleotide transcripts, unlike the original 126-nucl eotide transcript, added a single nucleotide prior to N un arrest (Fig. 4B, lane 8). The same pattern of transcription elongation and arrest was seen when the order of addition of N un and GreB was reversed or when both proteins were added simultaneously (data not shown). Recall that the stalled complexes 122 and 124 also arrested after the incorporation of a single nucleotide (Fig. 1B,D). Figure 4B al so shows that $\mathrm{N}$ un has weak GreB-like activity. A portion of the transcript in the 126 complex was cleaved to 124 nucleotide nt after 15 min incubation with N un (cf. lanes 1 and 3).

The effect of $\mathrm{N}$ un on the spontaneously arrested 151 complex is al so shown in Figure 4. The 151-nucl eotide transcript fails to elongate either in the presence or absence of $\mathrm{N}$ un (lanes 2,4). That the transcript is still engaged in the complex is shown by its efficient cleavage when exposed to GreB (lanes 5). Transcript cl eavage reactivated the complex, and the shortened transcripts el ongated upon incubation with NTPs (lanes 6). The 151 complex was sensitive to GreB-stimulated transcript cleavage in the presence of $\mathrm{N}$ un (lanes 7). As shown above for the 126 complex, the cleaved transcripts incorporated a singl e nucleotide prior to $\mathrm{N}$ un-mediated arrest (lanes 8). We conclude that Nun modification persists 
after transcript cleavage stimulated by GreB and limits subsequent elongation to a single nucleotide.

\section{Effects of Nun modification on} RNA pyrophosphorolysis

We wondered whether, in addition to blocking RN A polymerization, Nun also inhibited the reverse reaction, RNA pyrophosphorolysis. Elongation complexes were incubated with pyrophosphate over a broad range of concentrations (0.1-100 $\mu \mathrm{m})$ to determine the sensitivity of their nascent transcripts to pyrophosphorolysis (Fig. 5). Complex 125 was the most sensitive; the terminal nucleotide of the 125-nucleotide transcript was cleaved at $0.1 \mu \mathrm{M}$ pyrophosphate (Fig. 5D, lane 3). Other complexes were cleaved only at $\geqslant 1 \mu \mathrm{m}$ pyrophosphate. The sensitivity of a complex to GreB was unrelated to its sensitivity to pyrophosphate. At $>10 \mu \mathrm{m}$ pyrophosphate, all nascent transcripts underwent multiple rounds of pyrophosphorolysis (Fig. 5A-E, lanes 5,6).

We next determined how exposure to $\mathrm{N}$ un, in the absence of NTPs, affected the pyrophosphate sensitivity of several stalled or paused transcription complexes (Fig. $6 A-D)$. The response of each of these Nun-modified complexes to pyrophosphate was unique.

Incubation of complex 119 with $\mathrm{N}$ un did not protect it from repeated transcript cleavage (Fig. 6A). At $10 \mu \mathrm{m}$ pyrophosphate or below, the treated complex was limited to three rounds of pyrophosphorolysis (lane 5). That the complex was arrested was indicated by the incorporation of only one nucleotide upon subsequent addition of NTPs (lane 7). The efficiency of arrest at this site was reduced at higher pyrophosphate concentrations (lane 6).

$\mathrm{N}$ un modification protected complex 122 against pyrophosphorolysis (Fig. 6B, Ianes 2-6). The modified complex added a single nucleotide prior to arrest, either in the presence or absence of pyrophosphate (Fig. 6B, lanes $1,7)$.
Complex 125 retained its exquisite sensitivity to pyrophosphate after exposure to $\mathrm{N}$ un. Although the terminal nucleotide was still removed at $0.1 \mu \mathrm{m}$ pyrophosphate, there was no further transcript cleavage, even at $100 \mu \mathrm{M}$ pyrophosphate (Fig. 5D and 6C, cf. lanes 3-6). The single nucleotide removed by pyrophosphorolysis was reincorporated when NTPs were subsequently added (Fig. 6C, lane 7). Recall that complex 125 arrested without nucleotide addition (Fig. 6C, lane 1).

The GreB-sensitive complexes 126 and 151 were compl etely refractory to pyrophosphorolysis after $\mathrm{N}$ un modification (Fig. 6D, lanes 3-6). Incubation of complex 126 with $\mathrm{N}$ un resulted in partial cleavage of the transcript, principally to a 124-nucleoti de transcript (Fig. 6D, Iane 2) as described above (Fig. 4, lane 3). The 124-nucleotide transcri pt was likewise resistant to pyrophosphate cleavage. When incubated with NTPs, the cleaved complex arrested after incorporating one nucleotide (lane 1), resembling the $\mathrm{N}$ un-treated el ongation complex 124 (Fig. 1D).

The properties of the different complexes before and after $\mathrm{N}$ un treatment are summarized in Table 1.

\section{Pyrophosphate sensitivity of Nun-arrested complexes}

We then examined the pyrophosphate sensitivity of complexes arrested in the presence of Nun and NTPs. A rrested complexes 122, 123, 125, and 126 were obtained by incubating el ongation complexes 119, 122, 125, and 126, respectively, with N un and NTPs and then removing unreacted NTPs by gel filtration. Arrest was confirmed by demonstrating that the complexes could not el ongate upon the addition of NTPs (Fig. 6E-H, lanes 1 ). The transcript of arrested complex 126 was totally resistant to pyrophosphate (Fig. 6H, lanes 3-6). In contrast, the terminal nucleotides in the transcripts of arrested complexes 122, 123, or 125 were efficiently cleaved by pyrophosphate at $0.1 \mu \mathrm{m}$ (Fig. 6E-G, lanes 3). The short-

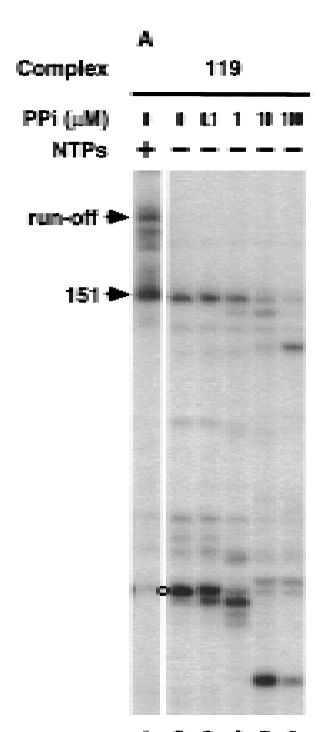

123456

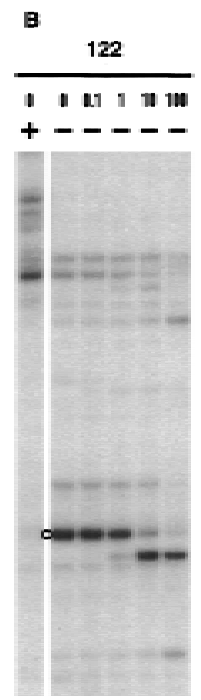

123456

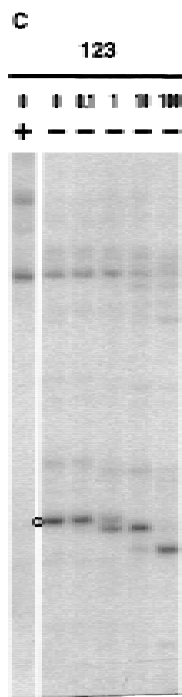

123456

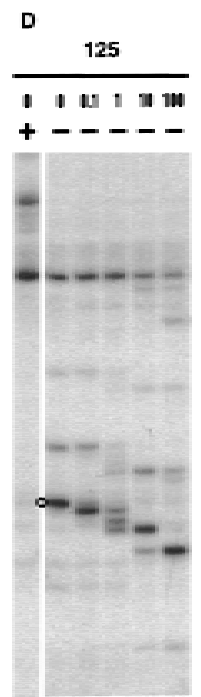

123456

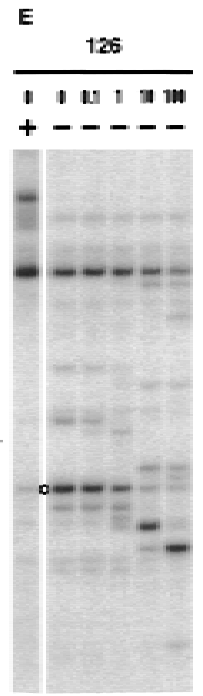

123456
Figure 5. RNA pyrophosphorolysis of transcription complexes. Transcription complexes (lanes 2) were chased with NTPs (lanes 1) or incubated with sodium pyrophosphate $(\mathrm{PPi})$ at the indicated concentrations for 15 min (lanes 3-6). 
Figure 6. Effects of Nun on RNA pyrophosphorolysis. (A-D) N un-treated complexes 119, 122, 125, and 126 (lanes 2) were prepared by preincubating the corresponding el ongation complexes with $\mathrm{N}$ un for $5 \mathrm{~min}$. The transcript of such a complex is indicated by a shaded circle on the left. (E-H) N un-arrested complexes 122, 123,125 , and 126 (lanes 2) were prepared from $\mathrm{N}$ un-treated complexes 119, 122, 125 and 126 , respectively, by chasing with NTPs and then removing unincorporated NTPs. The complexes were then incubated with sodium pyrophosphate $(\mathrm{PPi})$ at the indicated concentrations for $15 \mathrm{~min}$ (lanes 3-7) and/or chased with NTPs (lanes 1,7).

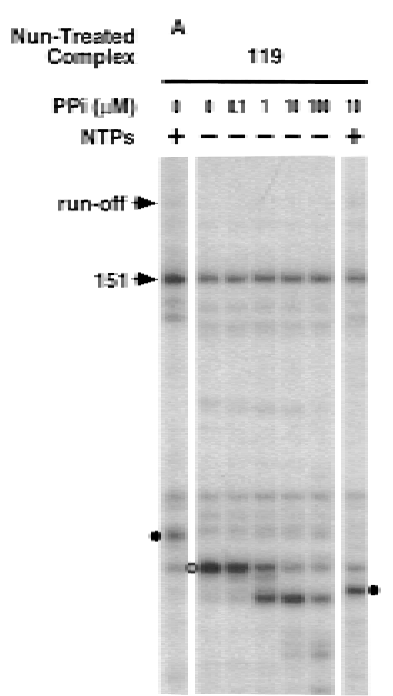

1234567
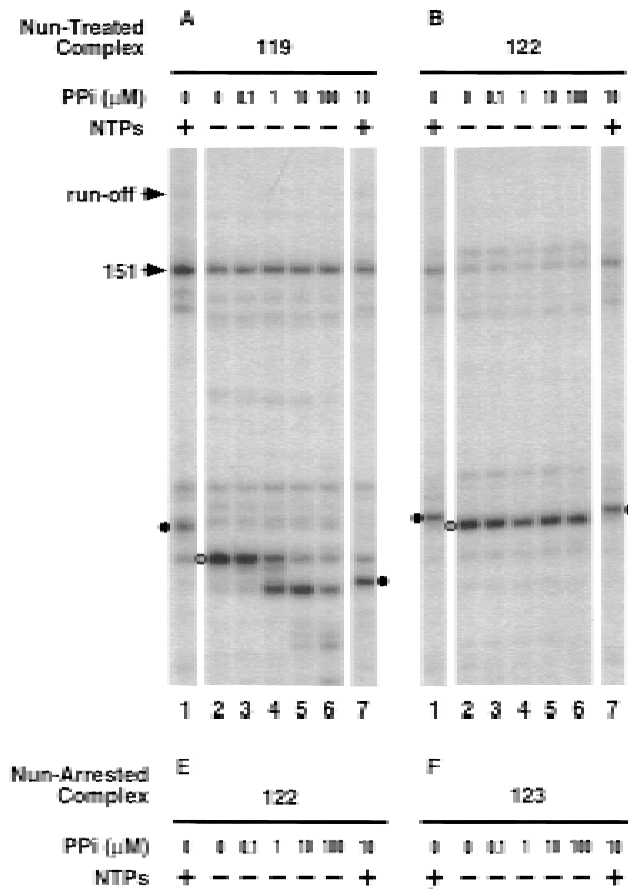

$F$

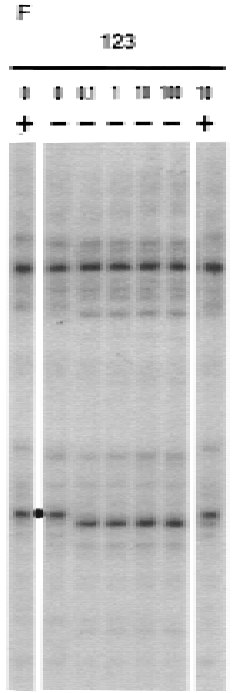

1234567

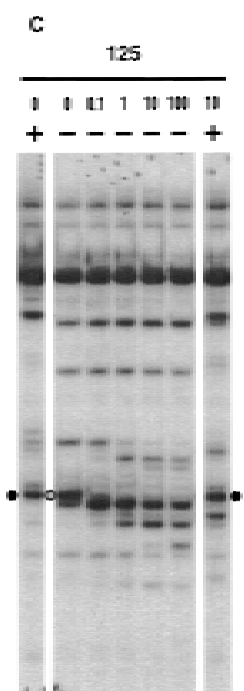

D

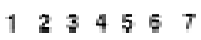

G
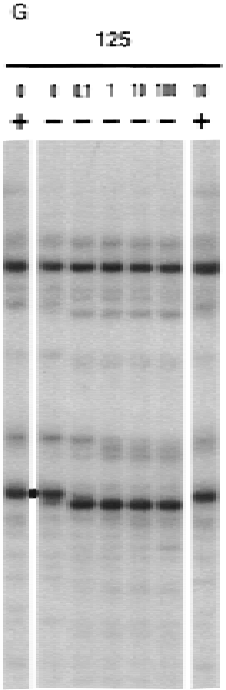

1234567

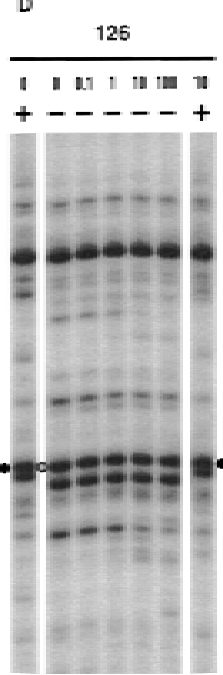

1234567
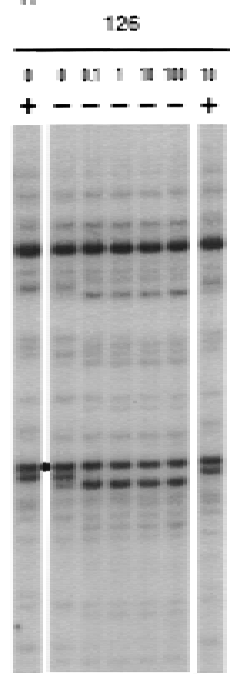

1234567 ened transcript was then completely refractory to pyrophosphorolysis (Fig. 6E-G, Ianes 3-6). After pyrophosphorolysis, the arrested complexes reincorporated only the cleaved nucleotide (Fig. 6E-G, lanes 7). These responses to pyrophosphate and NTPs were identical in all arrested GreB-resistant complexes (data not shown). Thus, the ultimate nucl eotide incorporated in the presence of $\mathrm{N}$ un is sensitive to pyrophosphorolysis, but all other nucleotides are resistant. How this unique pattern of pyrophosphorolysis may reflect the special conformation of the arrested complex is discussed below.

\section{Discussion}

\section{Elongation complexes vary in their response to Nun}

U sing an interrupted el ongation strategy, we have shown that the HKO22 N un protein inhibits RNA polymerization by RN AP elongation complexes paused at or walked to and stalled at various positions on a $\lambda$ DNA template. We have also demonstrated that there is a slow step in the $\mathrm{N}$ un-induced reaction. This explains why $\mathrm{N}$ un arrest sites are associated with intrinsic pause sites in a continuous el ongation assay (Hung and Gottesman 1995). Nun-induced transcription arrest is not specific to paused complexes. In fact, RN AP located at a pause site may be resistant to full modification by $\mathrm{N}$ un (see below).

$\mathrm{N}$ un also inhibits the reverse reaction of RNA polymerization; transcripts in arrested complexes are resistant to extensive pyrophosphorolysis. We suggest that these properties reflect a common feature of the $\mathrm{N}$ un reaction, namely that Nun blocks both forward and backward translocation of the nascent transcript in the elongation complex. The complexes that we have analyzed differ with respect to the sensitivity of their transcripts to pyrophosphorolysis and to cleavage induced by the E. coli GreB protein. They also vary in how they 
Table 1. A summary of the properties of $\lambda p_{\mathrm{L}}$ transcription complexes observed in this study

\begin{tabular}{|c|c|c|c|c|c|c|c|c|c|c|}
\hline \multirow[b]{3}{*}{ Complex } & \multirow[b]{3}{*}{ Nun } & \multirow{2}{*}{\multicolumn{2}{|c|}{$\begin{array}{c}\text { Nucleotide } \\
\text { incorporation }\end{array}$}} & \multicolumn{4}{|c|}{ Pyrophosphorolysis ${ }^{a}$} & \multirow{2}{*}{\multicolumn{2}{|c|}{$\begin{array}{c}\text { GreB } \\
\text { sensitivity }\end{array}$}} & \multirow{3}{*}{$\begin{array}{c}\text { Preferred } \\
\text { configuration }^{c}\end{array}$} \\
\hline & & & & \multicolumn{2}{|c|}{$0.1 \mu \mathrm{M}$ PPi } & \multicolumn{2}{|c|}{$10 \mu \mathrm{M} \mathrm{PPi}$} & & & \\
\hline & & - & + & - & + & - & + & - & + & \\
\hline 119 & & $\mathrm{U}$ & 3 & 0 & 0 & $U$ & 3 & $\mathrm{R}$ & $\mathrm{R}$ & paused \\
\hline 122 & & $U$ & 1 & 0 & 0 & $U$ & 0 & $\mathrm{R}$ & $\mathrm{R}$ & poly. (I) \\
\hline 125 & & $\mathrm{U}$ & 0 & 1 & 1 & $U$ & 1 & $\mathrm{R}$ & $\mathrm{R}$ & pyro. (II) \\
\hline 126 & & $\mathrm{U}$ & 0 & 0 & 0 & $U$ & 0 & $\mathrm{~S}$ & $\mathrm{~S}$ & endo. (III) \\
\hline 151 & & 0 & 0 & 0 & 0 & $U$ & 0 & $\mathrm{~S}$ & $\mathrm{~S}$ & endo. (III) \\
\hline
\end{tabular}

Each complex is identified by the number of nucleotides in its transcript. The properties of each complex with $(+)$ or without $(\rightarrow)$ preincubation with $\mathrm{N}$ un are shown.

${ }^{a}(U)$ An unlimited reaction. When a limited reaction occurs, the number of nucleotides incorporated or removed is indicated.

${ }^{b}(R$ or $S) G$ reB resistant or GreB sensitive, respectively.

'Poly., pyro., and endo. are abbreviations for polymerization-, pyrophosphorolysis-, or endonucleolysis-ready configuration, respectively; the bracketed Roman numeral refers to the structure in Figure 7 that depicts the corresponding configuration. The preferred configuration of the paused complex 119 cannot be determined by the observed properties and is thus label ed paused. (See text for a detailed discussion.)

respond to $\mathrm{N}$ un. Based on these characteristics, we suggest that the various paused and stalled complexes represent different and structurally distinct intermediates in the elongation cycle.

Structure and properties of a transcription elongation complex

Although direct visualization of RNAP is only now becoming possible (Polyakov et al. 1995), the analysis of its enzymatic properties has yiel ded consi derable structural information. Transcribing RN AP interacts with the 3'proximal nucleotides of the nascent transcript through the product-binding $(\mathrm{P})$ site of the protein (Krakow and Fronk 1969; see Chan and Landick 1994). The RNAP active center includes a nucleotide-binding $(\mathrm{N})$ site that can accommodate either a nucleotide in the nascent transcript or the nucleoside monophosphate moiety of the substrate NTP. Phosphodiester bonds are formed or disrupted $5^{\prime}$ to the $\mathrm{N}$ site. These RNAP sites and the nascent transcript in an el ongating complex are depicted in Figure 7.

To support RNA polymerization, the $\mathrm{N}$ site must be located immediately downstream to the $3^{\prime}$-hydroxyl of the nascent transcript. Structure I depicts such a polymerization-ready RNAP, in which the $\mathrm{N}$ site is vacant. The appropriate NTP then enters the N site and forms a phosphodiester bond with the 3'-hydroxyl of the nascent transcript, yielding structure II. Further nucl eotide incorporation requires downstream translocation of the RNAP, which places the new 3'-hydroxyl nucl eotide upstream of the N site (structure I'; which is configurationally equivalent to structure I). Processive RNA polymerization occurs by repeated nucleotide incorporation and translocation (Fig. 7, downward-pointing arrows).

Pyrophosphorolysis is the reverse reaction of RNA poIymerization. Both reactions are thought to be carried out by the same active center (Krakow and Fronk 1969). In contrast to el ongation, pyrophosphorolysis requires that the $3^{\prime}$-terminal nucleotide of the nascent transcript be located in the $\mathrm{N}$ site, as shown in structure II (the pyrophosphorolysis-ready form). Pyrophosphate cleaves the 3'-most phosphodiester bond by a nucleophilic attack on the phosphorus atom (Rozovskaya et al. 1984). Removal of the NTP by-product yields structure I. A second round of pyrophosphorolysis occurs when upstream translocation of RN AP feeds the newly created 3 '-terminal nucleotide into the $\mathrm{N}$ site, producing structure II', which is configurational ly equivalent to structure II. Processive pyrophosphorolysis entails repeated bond breakage and translocation (Fig. 7, upward-pointing arrows) and may require higher pyrophosphate concentrations than the removal of the initial 3 '-terminal nucleotide (Kassavetis et al. 1986).

Endonucleolytic hydrolysis of nascent transcripts has been demonstrated in both prokaryotic and eukaryotic systems (Surratt et al. 1991; see Reines 1994). An RN APassociated factor, such as GreA or GreB for E. coli RN AP (Borukhov et al. 1992, 1993), or TFIIS for RN APII (Izban and Luse 1992; Reines 1992; Guo and Price 1993) stimulates hydrolytic cleavage at a phosphodiester bond two or more nucleotides from the transcript $3^{\prime}$ terminus. The small oligonucleotide product is released, whereas the upstream portion of the transcript remains engaged and can be elongated. Although efficient cleavage occurs in vitro only in the presence of a stimulatory factor, hydrolytic transcript cleavage is an intrinsic activity of the RNAP (Orlova et al. 1994; Rudd et al. 1994) and is believed to be promoted by the RN AP active center (Rudd et al. 1994). The active center can approach the scissile phosphodiester bond by upstream sliding of RN AP al ong the transcript (Komissarova and Kashlev 1997; N udler et al. 1997), as shown in Figure 7, structure III (the endonucleolysis-ready form). Structure III is incapable of transcript el ongation. Cleavage and the release of the downstream oligonucleotide product regenerates structure I and permits resumption of RN A polymerization.

With the exception of complex 151, all of the com- 


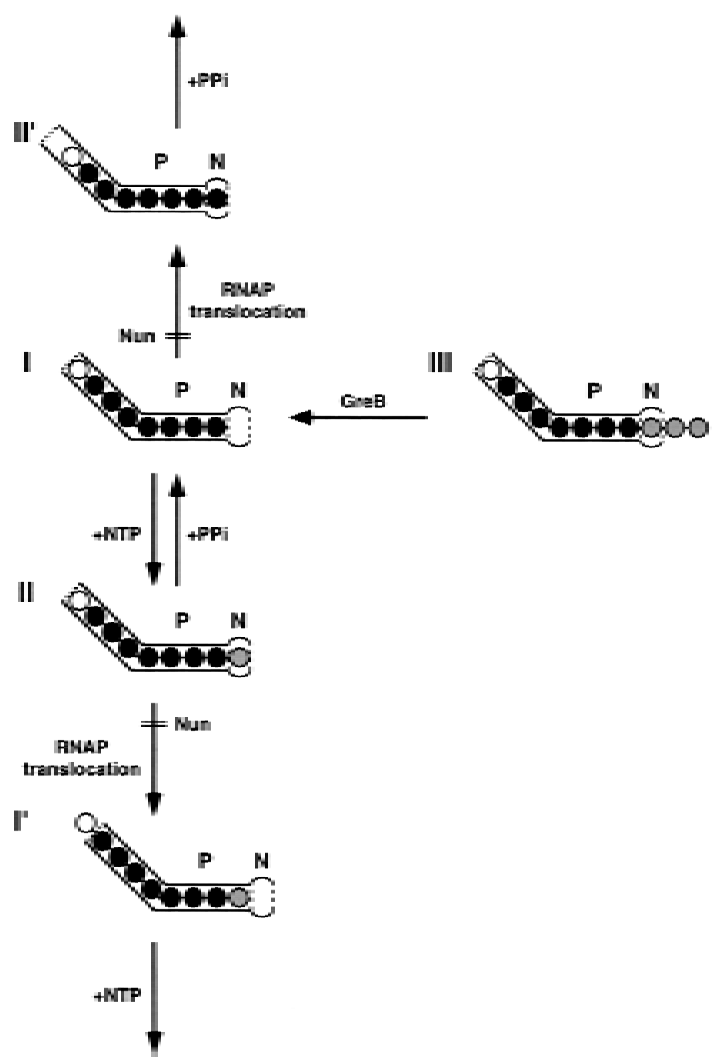

Figure 7. A model for the action of $\mathrm{N}$ un on transcription complexes. Each numbered structure represents a transcription complex at a particular transitional stage during el ongation. An arrow between two structures indicates a transition. Transitions that involve RN AP translocation are indicated, as is the substrate/ factor required for a transition. A transition inhibited by $\mathrm{N}$ un is shown by double lines label ed $\mathrm{N}$ un. In each structure, the bent rectangle represents the product-binding $(\mathrm{P})$ site of RN AP. The oval represents the nucleotide-binding (N) site of the active center of RN AP. The circles represent nucleotides in the nascent transcript. To help visualize the translocation of RN AP, some circles are shaded differently to identify particular nucleotides in the transcript. The number of nucleotides accommodated by the product-binding site is arbitrarily depicted. (See text for detailed description.)

plexes in this study were el ongation proficient. All of the nascent transcripts were cleaved at high concentrations of pyrophosphate or GreB. Our data are consistent with the idea that a particular transcription complex is in equilibrium among various structures, although one structure may predominate. Presumably, sensitivity to pyrophosphate, GreB, or N un reflects the population distribution of these various structures, although other possibilities have not been excluded. Thus, complex 125 , which is particularly sensitive to pyrophosphate, exists largely in the pyrophosphorolysis-ready form (structure II). Complex 126 is in equilibrium between an el ongation proficient form and a GreB-sensitive, presumably inactive, form (structure III). Complex 119 or 122, which is relatively resistant to both transcript cl eavage reactions, may be in equilibrium between the polymerizationready form (structure I) and another configuration.

\section{How Nun induces transcription arrest}

Our data show that $\mathrm{N}$ un acts by inhibiting the translocation of RN AP. The 3'-terminal nucleotide of a GreBresistant complex arrested by $\mathrm{N}$ un is highly susceptible to pyrophosphorolysis, arguing that the arrested complex is in the pyrophosphorolysis-ready form (Fig. 7, structure II). However, the complex is totally resistant to a second round of pyrophosphorolysis. Moreover, the arrested complex can reincorporate only the single cleaved nucleotide. The arrested complex is therefore limited to making and breaking the same phosphodiester bond. This indicates that the active center of the $\mathrm{N}$ un-arrested complex retains its catalytic activities but cannot translocate relative to the nascent transcript.

Translocation of RNAP entails the shifting of the active center and the nucleic acid-binding channels relative to RN A and DNA, the unwinding and rewinding of DNA at the promoter-distal (downstream) and promoter-proximal (upstream) edges of the transcription bubbles, respectively, and the unwinding of the RN A-DN A heteroduplex near the upstream edge of the transcription bubble. Inhibition of any one of these activities would prevent translocation of RNAP. It is not yet known which of these activities is/are blocked in a N un-modified RNAP.

As predicted from this model of $\mathrm{N}$ un action, complex 125, which is in the pyrophosphorolysis-ready form, with the $\mathrm{N}$ site occupied, is arrested without nucleotide incorporation. Complex 122 is in the polymerizationready form (structure I). By preventing translocation of RNAP upstream, $\mathrm{N}$ un blocks the filling of the $\mathrm{N}$ site with the transcript 3'-OH terminus, and pyrophosphorolysis cannot take place. Because complex 122 has a vacant $\mathrm{N}$ site, it can incorporate one, but only one, nucleotide after $\mathrm{N}$ un modification.

This mechanism al so explains the response of a GreBsensitive complex to $\mathrm{N}$ un. We assume that $\mathrm{N}$ un modifies a GreB-sensitive complex after upstream translocation of the RNAP. This configuration (structure III) is maintained in the modified complex, preventing both elongation and pyrophosphorolysis. GreB-stimulated transcript cleavage converts the modified complex to structure I, and it can now incorporate one nucleotide prior to arrest.

The spontaneously paused complex 119 differs from the stalled complexes described above. After exposure to $\mathrm{N}$ un, this complex can undergo multiple rounds of nucleotide incorporation or pyrophosphorolysis prior to arrest. It appears that $\mathrm{N}$ un is unable to modify fully RNAP paused at position 119 and that translocation arrest takes effect only after the RNAP has moved to an upstream or downstream position. Interestingly, most of the complexes isolated directly from kinetically interrupted elongation reactions undergo more than one round of nucleotide incorporation or pyrophosphorolysis after incubation with $\mathrm{N}$ un. The special configuration(s) 
of these paused compl exes (Chan et al. 1997) may render them resistant to full modification by $\mathrm{N}$ un.

\section{Spontaneous and Nun-mediated elongation arrest}

Borukhov et al. (1993) suggest that spontaneously arrested compl exes arise when the RN AP active center and $3^{\prime}$ terminus of the nascent transcript misalign. GreBstimulated cleavage removes the protruding 3 ' nucleoti des and permits further el ongation. The response of the spontaneously arrested 151 complex to $\mathrm{N}$ un is consistent with this model. Complex 151 is unable to el ongate prior to treatment with GreB, although it undergoes transcript cleavage at high pyrophosphate concentrations. The 151 RNAP is therefore capable of some upstream movement. By blocking the translocation of RNAP, N un renders complex 151 entirely resistant to pyrophosphate. As expected, the $\mathrm{N}$ un-modified complex remains sensitive to $\mathrm{GreB}$ and is reactivated by GreBinduced cleavage. The reactivated complex, however, adds only a single nucl eotide, implying that GreB-stimulated cleavage generates a compl ex of the type I structure that remains modified by $\mathrm{N}$ un.

\section{Materials and methods}

Nun protein was purified as described (Chattopadhyay et al. 1995). RN AP was purified according to Burgess and Jendrisak (1975) from E. coli strain AD8571, which carries disrupted greA and greB genes (Orlova et al. 1995). GreB protein was a generous gift from Dr. S. Borukhov (State University of N ew York Health Science Center, Brooklyn). [ $\alpha-{ }^{32}$ P]N TPs and unlabel ed ultrapure NTPs were purchased from Amersham and Pharmacia, respectively.

Transcription complexes are identified by the lengths of their nascent transcripts, for example, a complex containing a nascent transcript of 100 nucleotides is denoted as complex 100. The DNA template used for all experiments presented in this paper contained the phage $\lambda$ sequence from the coordinates 35422-35660, including the $p_{L}$ promoter and the nutL sequence; the runoff transcript is 161 nucleotides. The template was prepared as described (Hung and Gottesman 1995), except the following oligonucleotides were used as primers for PCR: $5^{\prime}$ CATACAGATAACCATCTGCGGTG-3' and 5'-CCCCGCGATTGGCACATTCGGAGC-3'.

The transcription buffer and the synthesis of the minus UTP starter 15 complex were essentially as described (Hung and Gottesman 1995), except that the DN A template, RNAP, and GTP were used at $100 \mathrm{~nm}, 300 \mathrm{~nm}$, and $150 \mu \mathrm{m}$, respectively. GTP concentration was increased to suppress transcript slippage at the $\lambda p_{L}$ promoter (Severinov and Goldfarb 1994). To obtain paused complex 119, a mixture of rifampicin, ATP, and other NTPs was added to complex 15 so that the final concentrations of the respective components were $10 \mu \mathrm{g} / \mathrm{ml}, 3 \mu \mathrm{m}$, and $150 \mu \mathrm{m}$, respectively. Elongation was permitted for $1 \mathrm{~min}$ and hal ted by adding EDTA to $50 \mathrm{~mm}$. To remove NTPs and EDTA from the transcription complex, the bovine serum albumin content of the reaction was first adjusted to $1.25 \mathrm{mg} / \mathrm{ml}$, and a portion $(<30 \mu \mathrm{l})$ of the mixture was loaded onto a BioSpin 30 gel filtration spin column (Bio-Rad) pre-equilibrated with transcription buffer. The loaded column was spun at $1000 \mathrm{~g}$ for $15 \mathrm{~min}$ at $4^{\circ} \mathrm{C}$, and the filtrate, which contained the transcription complex, was saved. To walk to various downstream template sites, the complex was incubated with appropriate combinations of NTPS for $10 \mathrm{~min}$ at $12^{\circ} \mathrm{C}$. The final concentration of NTP used to walk a transcription complex from an intrinsic pause site was $5 \mu \mathrm{M}$; to walk from other sites, the NTP concentration was $0.5 \mu \mathrm{M}$. After each walk, NTPs were removed by gel filtration chromatography as described above. Counting from the transcription start site of the $\lambda p_{L}$ operon, the nontemplate sequence from 120 to 128 nucleotides is AAGT GCGAT. Thus, complexes 122 and 124 were obtained by walking complex 119 with ATP +GTP and ATP + GTP +UTP, respectively; complex 123 by walking complex 122 with UTP; complexes 125,126 , and 127 by walking complex 124 with CTP, CTP + GTP, and ATP + CTP + GTP, respectively. To complete transcription el ongation, that is, to chase a particular complex, all four NTPs were added to 50 $\mu \mathrm{M}$ each. Where indicated, $\mathrm{N}$ un was added at $500 \mathrm{~nm}$. After each addition of protein factor or reagent, samples were incubated at $32^{\circ} \mathrm{C}$ for $5 \mathrm{~min}$ prior to the next step, unless otherwise indicated. The transcription products were treated as described (Hung and Gottesman 1995) and el ectrophoresed on a $40 \times 35 \times$ $0.4-\mathrm{cm} 6 \%$ polyacrylamide/ $8.3 \mathrm{~m}$ urea gel at a constant power of $100 \mathrm{~W}$ until the xylene cyanol FF dye had migrated for $35 \mathrm{~cm}$. Radiolabeled transcripts were detected by autoradiography.

In most assays a spontaneously arrested complex at 151 nucleotides was detected. A rrest at 151 nucleotides is template, but not sequence, specific. The 151 complex was not observed in transcription assays using the template described above but carrying additional downstream DN A (data not shown). We suggest that spontaneous arrest at 151 nucleotides was most likely caused by the loss of RNAP-DNA contact because of the proximity of the elongating RN AP to the end of the template (Izban et al. 1995).

To improve the efficiency of the N un reaction to $\sim 100 \%$, we used high $\mathrm{N}$ un concentrations. At these levels, $\mathrm{N}$ un activity is independent of the $\lambda$ nut site (data not shown). We believe, however, that our results do reveal the mechanism of $\mathrm{N}$ un action, as high $\mathrm{N}$ un concentrations stimulate but do not affect the essential characteristics of the $\mathrm{N}$ un reaction. Thus, the sites of arrest and the susceptibility of the arrested complexes to transcript cleavage shown here are also seen at low $\mathrm{N}$ un levels, when $\lambda$ nut is required (data not shown). As discussed previously (Chattopadhyay et al. 1995), it is likely that the $\lambda$ nut sequence in the nascent transcript serves only to increase the local $\mathrm{N}$ un concentration in the vicinity of RNAP and can be compensated for by high N un concentrations. Similarly, overexpression of $\mathrm{N}$ un is known to enhance termination on mutant $\lambda$ nut sequences in vivo (Baron and Weisberg 1992).

\section{Acknowledgments}

Wethank Dr. S. Borukhov for providing GreB protein and Dr. A. Das for providing E. coli strain AD8571. We are grateful to Drs. M. Kashlev, E. N udler, and K. Severinov for technical advice and R.S. Watnick for reading the manuscript. This work was supported by N ational Institutes of Heal th grant GM 37219.

The publication costs of this article were defrayed in part by payment of page charges. This article must therefore be hereby marked "advertisement" in accordance with 18 USC section 1734 solely to indicate this fact.

\section{References}

Arndt, K.M. and M.J. Chamberlin. 1990. RN A chain elongation by Escherichia coli RNA polymerase. Factors affecting the stability of el ongating ternary complexes. J. Mol. Biol. 213: 79-108. 
Baron, J. and R.A. Weisberg. 1992. Mutations of the phage $\lambda$ nutL region that prevent the action of $\mathrm{N}$ un, a site-specific transcription termination factor. J. Bacteriol. 174: 19831989.

Borukhov, S., A. Polyakov, V. Nikiforov, and A. Goldfarb. 1992. GreA protein: A transcription elongation factor from Escherichia coli. Proc. Natl. Acad. Sci. 89: 8899-8902.

Borukhov, S., V. Sagitov, and A. Goldfarb. 1993. Transcript cleavage factors from E. coli. Cell 72: 459-466.

Burgess, R.R. and J.J. Jendrisak. 1975. A procedure for the rapid, large-scale purification of Escherichia coli DNA-dependent RNA polymerase involving Polymin $\mathrm{P}$ precipitation and DNA-cellulose chromatography. Biochemistry 14: 46344638.

Chan, C.L. and R. Landick. 1994. New perspectives on RNA chain elongation and termination by E. coli RNA polymerase. In Transcription: Mechanisms and regulation (ed. R.C. Conaway and J.W. Conaway), pp. 297-321. Raven Press, N ew York, NY.

Chan, C.L., D. Wang, and R. Landick.1997. Multiple interactions stabilize a single paused transcription intermediated in which hairpin to $3^{\prime}$ end spacing distinguishes pause and termination pathway. J. Mol. Biol. 268: 54-68.

Chattopadhyay, S., S.C. Hung, A.C. Stuart, A.G. Palmer III, J. Garcia-Mena, A. Das, and M.E. Gottesman. 1995. Interaction between the phage HK022 Nun protein and the nut RN A of phage $\lambda$. Proc. Natl. Acad. Sci. 92: 12131-12135.

Guo, H. and D.H. Price. 1993. Mechanism of DmS-II-mediated pause suppression by Drosophila RN A polymerase II. J. Biol. Chem. 268: 18762-18770.

Hung, S.C. and M.E. Gottesman. 1995. Phage HK022 N un protein arrests transcription on phage $\lambda$ DNA in vitro and competes with the phage $\lambda \mathrm{N}$ antitermination protein. J. Mol. Biol. 247: 428-442.

Izban, M.G. and D.S. Luse. 1992. Factor-stimulated RNA polymerase II transcribes at physiological elongation rates on naked DN A but very poorly on chromatin templates. J. Biol. Chem. 267: 13647-13655.

Izban, M.G., I. Samkurashvili, and D.S. Luse. 1995. RN A polymerase II ternary complexes may become arrested after transcribing to within 10 bases of the end of linear templates. J. Biol. Chem. 270: 2290-2297.

Kassavetis, G.A., P.G. Zentner, and E.P. Geiduschek. 1986. Transcription at bacteriophage T4 variant late promoters. An application of a newly devised promoter-mapping method involving RNA chain retraction. J. Biol. Chem. 261: 14256-14265.

Komissarova, N. and M. Kashlev. 1997. RNA polymerase switches between inactivated and activated states translocating back and forth along the DNA and the RNA. J. Biol. Chem. 272: 15329-15338.

Krakow, J.S. and E. Fronk. 1969. Azotobacter vinelandii ribonucleic acid polymerase. 8. Pyrophosphate exchange. J. Biol. Chem. 244: 5988-5993.

Nudler, E., A. Goldfarb, and M. Kashlev. 1994. Discontinuous mechanism of transcription elongation. Science 265: 793796.

Nudler, E., M. Mustaev, E. Lukhtanov, and A. Goldfarb. 1997. The RNA-DNA hybrid maintains the register of transcription by preventing backtracking of RNA polymerase. Cell 89: 33-41.

Orlova, M., J. N ewlands, A. Das, A. Goldfarb, and S. Borukhov. 1995. Intrinsic transcript cleavage activity of RN A polymerase. Proc. Natl. Acad. Sci. 92: 4596-4600.

Polyakov, A., E. Severinova, and S.A. Darst. 1995. Three-dimensional structure of E. coli core RNA polymerase: Promoter binding and elongation conformations of the enzyme. Cell 83: $365-373$.

Reines, D. 1992. Elongation factor-dependent transcript shortening by template-engaged RNA polymerase II. J. Biol. Chem. 267: 3795-3800.

- - - 1994. N ascent RN A cleavage by transcription elongation complexes. In Transcription: Mechanisms and regulation (ed. R.C. Conaway and J.W. Conaway), pp. 263-278. Raven Press, N ew York, NY.

Robert, J., S.B. Sloan, R.A. Weisberg, M.E. Gottesman, R. Robledo, and D. Harbrecht. 1987. The remarkable specificity of a new transcription termination factor suggests that the mechanisms of termination and antitermination are similar. Cell 51: $483-492$.

Robledo, R., M.E. Gottesman, and R.A. Weisberg. 1990. $\lambda$ nutR mutations convert $\mathrm{HK} 022 \mathrm{~N}$ un protein from a transcription termination factor to a suppressor of termination. J. Mol. Biol. 212: 635-643.

Robledo, R., B.L. Atkinson, and M.E. Gottesman. 1991. Escherichia coli mutations that block transcription termination by phage HK022 N un protein. J. Mol. Biol. 220: 613-619.

Rozovskaya, T.A., V.O. Rechinsky, R.S. Bibilashvili, M. Karpeisky, N.B. Tarusova, R.M. Khomutov, and H.B. Dixon. 1984. The mechanism of pyrophosphorolysis of RNA by RNA polymerase. Endowment of RNA polymerase with artificial exonuclease activity. Biochem. J. 224: 645-650.

Rudd, M.D., M.G. Izban, and L.S. Luse. 1994. The active site of RN A polymerase Il participates in transcript cleavage within arrested ternary complexes. Proc. Natl. Acad. Sci. 91: 80578061.

Severinov, K., and A. Goldfarb. 1994. Topology of the product binding site in RNA polymerase revealed by transcript slippage at the phage $\lambda P_{\perp}$ promoter. J. Biol. Chem. 269: 3170131705.

Sloan, S.B. and R.A. Weisberg. 1993. U se of a gene encoding a suppressor tRNA as a reporter of transcription: Analyzing the action of the $\mathrm{N}$ un protein of bacteriophage HK022. Proc. Natl. Acad. Sci. 90: 9842-9846.

Surratt, C.K., S.C. Milan, and M.J. Chamberlin. 1991. Spontaneous cleavage of RNA in ternary complexes of Escherichia coli RN A polymerase and its significance for the mechanism of transcription. Proc. Natl. Acad. Sci. 88: 7983-7987. 


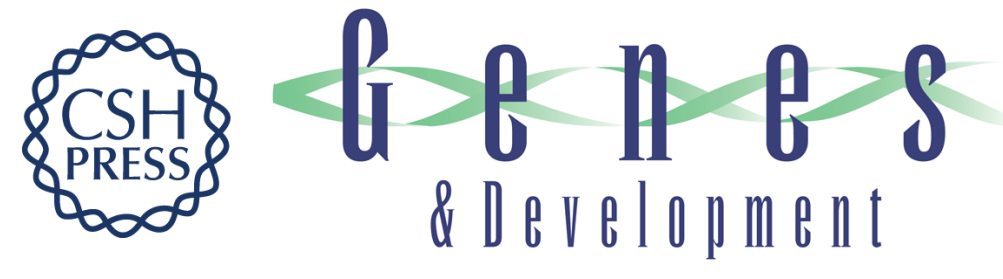

\section{The Nun protein of bacteriophage HK022 inhibits translocation of Escherichia coliRNA polymerase without abolishing its catalytic activities}

Siu Chun Hung and Max E. Gottesman

Genes Dev. 1997, 11:

Access the most recent version at doi:10.1101/gad.11.20.2670

References This article cites 27 articles, 17 of which can be accessed free at:

http://genesdev.cshlp.org/content/11/20/2670.full.html\#ref-list-1

License

Email Alerting Receive free email alerts when new articles cite this article - sign up in the box at the top Service right corner of the article or click here.

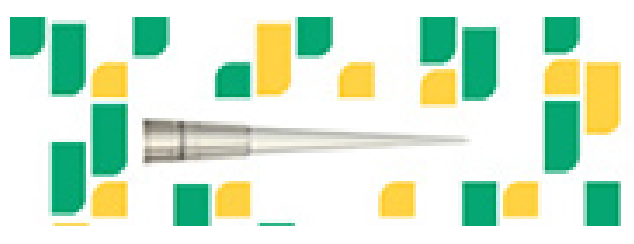

Focused on your science. 